\title{
RESEARCH
}

Open Access

\section{Role of QRS fragmentation in 12-lead surface ECG in prediction of isolated epicardial coronary artery ectasia and its anatomical distribution in patients without acute coronary syndromes}

Diaa Kamal ${ }^{1 *}$ and Moataz Hashem ${ }^{2}$

\begin{abstract}
Background: Coronary artery ectasia (CAE) is a form of abnormal coronary artery lumen dilatation associated with epicardial flow disturbances and microvascular dysfunction. QRS complex fragmentation (fQRS) in surface ECG is caused by abnormal depolarization due to myocardial ischemia and scarring. It has been proved in different studies to be positively correlated with adverse cardiac events. This study aimed to assess the role of fQRS as a noninvasive predictor of CAE and its anatomical distribution. A total of 100 patients referred for elective coronary angiography were included and divided into 2 groups: 50 patients with isolated CAE (group A) and 50 patients with angiographically normal coronaries (group B, control group). Both groups were compared regarding clinical, echocardiographic, and ECG characteristics.
\end{abstract}

Results: Univariate analysis showed a significant correlation between male sex, smoking, diabetes mellitus, increased systolic blood pressure, fQRS, echocardiographic evidence of diastolic dysfunction, and CAE ( $P$ values of $0.005,0.002,0.016,0.027,0.0001$, and 0.04 , respectively). Multivariate regression analysis showed that fQRS is the most important independent predictor for the presence of CAE $(P<0.00001)$ with sensitivity $94 \%$, specificity $88 \%$, PPV 88.7\%, and NPV 93.6\%. We also found a significant correlation between fQRS distribution in surface ECG and anatomical distribution of CAE [increased territories with multivessel affection $(P=0.00001)$, anterior leads with $L A D$ affection ( $P=0.00001)$, lateral and inferior leads with $L C X$ affection $(P=0.003$ and 0.04 , respectively), inferior leads with RCA affection $(P=0.00001)]$.

Conclusion: fQRS in surface ECG can potentially be used as an effective non-invasive method to predict isolated CAE and its anatomical distribution.

Keywords: 12-lead surface ECG, QRS fragmentation, Coronary ectasia, Coronary angiography

\footnotetext{
* Correspondence: drdiaaeldin@med.asu.edu.eg

${ }^{1}$ Cardiology Department, Faculty of Medicine, Ain Shams University, Abbasia

Street, Cairo, Egypt

Full list of author information is available at the end of the article
}

\section{Springer Open}

(0) The Author(s). 2020 Open Access This article is licensed under a Creative Commons Attribution 4.0 International License, which permits use, sharing, adaptation, distribution and reproduction in any medium or format, as long as you give appropriate credit to the original author(s) and the source, provide a link to the Creative Commons licence, and indicate if changes were made. The images or other third party material in this article are included in the article's Creative Commons licence, unless indicated otherwise in a credit line to the material. If material is not included in the article's Creative Commons licence and your intended use is not permitted by statutory regulation or exceeds the permitted use, you will need to obtain permission directly from the copyright holder. To view a copy of this licence, visit http://creativecommons.org/licenses/by/4.0/. 


\section{Background}

Coronary artery ectasia (CAE) is defined as an abnormal coronary dilatation (segmental or diffuse) $>1.5$ times the reference normal vessel either in the same artery or in other adjacent normal arteries [1]. Markis et al. classified CAE into 4 types (types 1, 2, and 3 for diffuse ectasia and type 4 for focal ectasia) [2]. Historically, both terms (ectasia and aneurysm) were interchangeably used to address coronary aneurysmal dilatation [3]. Recently, authors confined the "aneurysm" term for focal coronary dilatation leaving the "ectasia" term for more diffuse coronary aneurysmal dilatation [4].

CAE is seen in approximately $5 \%$ of cases undergoing coronary angiography (CA) for various indications [3]. The exact etiology of CAE is not fully understood. Atherosclerosis, iatrogenic injury, vasculitis, and genetic factors might have a causal role [5-7]. Despite being mostly asymptomatic, local thrombosis in ectatic coronaries with or without distal embolization can lead to acute ischemic events [3]. It is known that CAE disturbs flow in coronary arteries increasing blood viscosity which consequently enhances tendency towards thrombosis [8]. Stress-induced ischemia without obstructive CAD due to microvascular dysfunction have been documented in patients with $\mathrm{CAE}$, an abnormality commonly referred to as (dilated coronopathy) [9].

Long-term cardiovascular outcomes of patients with CAE suffering from acute coronary syndromes were always a question needing an answer. Doi et al. in their study showed a significant prognostic effect of CAE in these patients with improved outcomes in cases treated with therapeutic oral anticoagulation [10].

Fragmentation of QRS complex (fQRS) is an indicator of unsynchronized depolarization of myocardial fibers that may be attributed to myocardial ischemia or scarring that may even be subclinical [11]. Autopsy studies showed that a mixture of viable myocardium, necrotic myocardial fibers, and fibrosis is responsible for this finding in surface electrocardiogram (ECG) [12]. fQRS was repeatedly studied as an important prognosticator in different cardiac disorders [13-22].

Given the clinical consequences of CAE especially if it leads to an acute coronary syndrome, many studies were done trying to find predictors for this coronary abnormality [23-26]. fQRS despite being a very cheap and safe non-invasive method was not sufficiently studied as a potential predictor for isolated CAE. In our study, we tried to find if there is a significant correlation between isolated CAE and $\mathrm{fQRS}$ or not.

\section{Methods}

Our study was a prospective observational case control study that included 100 patients presented to our Center in the time interval from November 2016 to September 2017.

The study was approved by the Research Ethics Committee of our institute, and all patients signed an informed written consent for participation in the study in accordance with the Declaration of Helsinki. The study included stable patients indicated for elective CA [patients with chest pain and high pretest probability for CAD that have not done any non-invasive testing or those who proved to have high-risk findings in noninvasive testing (stress ECG, radioisotope scanning, stress echo, etc.)] according to the appropriateness criteria [27]. Patients were divided according to CA data into 2 groups: isolated CAE group (50 patients) and control group which consisted of 50 patients with angiographically normal coronaries.

\section{Exclusion criteria}

Patients with previous MI, pathological Q waves on ECG, QRS duration > $120 \mathrm{~ms}$, paced rhythm, any type of cardiomyopathy, renal impairment (serum creatinine > $2 \mathrm{mg} / \mathrm{dl}$ ), left ventricular hypertrophy (LVH) by ECG or by echocardiography, intake of anti-arrhythmic medications, and those who refused to sign the informed consent were excluded from the study.

All patients were subjected to proper history taking to obtain all clinical data regarding their demographic data, classic cardiovascular risk factors, and any previous medical history. Clinical examination was done including measuring arterial blood pressure (ABP). Transthoracic echocardiography was performed using a highperformance cardiovascular ultrasound system (Vivid S5 machine, GE healthcare Company, USA) with registration of various data.

\section{ECG acquisition and interpretation}

A 12-lead ECG machine (PageWriter TC20, Philips Medical Systems, USA) was used with the following parameters in recording: filter $0.16-100 \mathrm{~Hz}, \mathrm{AC}$ filter 60 $\mathrm{Hz}$, and speed $10 \mathrm{~mm} / \mathrm{mv}$ and $25 \mathrm{~mm} / \mathrm{s}$. fQRS was considered to be present if any of the different RSR' patterns was observed (additional $\mathrm{R}$ wave which is called R', more than one R' without a typical bundle branch block, notching of $\mathrm{R}$ or $\mathrm{S}$ waves) in 2 or more contiguous leads belonging to the same lead set representing territory of supply of a major coronary artery [28]. Anteroseptal leads were defined as leads $\mathrm{V}_{1}-\mathrm{V}_{2}$, anterior leads as leads $V_{1}-V_{4}$, anterolateral leads as leads $V_{1}-V_{6}$, high lateral leads as leads I and aVL, lateral leads as leads $\mathrm{V}_{4}-$ $\mathrm{V}_{6}$, and inferior leads as leads II, III, and aVF. ECG analysis was done without magnification. Fragmentation was considered positive if seen in all complexes of the recorded ECG lead. The longest QRS was used to detect QRS duration in any lead. ECG recordings of all patients 
were revised by another cardiologist blinded to clinical and angiographic findings of patients. Figure 1 shows a diagrammatic illustration of different patterns of fQRS in one of our study population.

\section{Invasive CA}

Invasive $\mathrm{CA}$ was done using the Judkins technique via femoral access. Patient was considered to have isolated CAE if there was abnormal coronary dilatation segmental or diffuse (but not focal) $>1.5$ times the reference normal vessel either in the same artery or in other adjacent normal arteries [1] with no stenosis. Normal coronaries are those without CAE, stenosis, or atherosclerotic irregularities. Based on data from CA, patients were divided into 2 groups (isolated CAE vs. normal coronaries) each containing 50 patients. The 2 groups were compared regarding all study variables to see if there were any significant differences.

\section{Statistical analysis}

Analysis was performed using the Statistical Package for the Social Sciences (SPSS) version 22.0 for Windows (SPSS Inc., Chicago, IL, USA). Categorical variables were described as percentages. Continuous variables were described as mean \pm SD. Categorical data were compared using the $\chi^{2}$ test. Continuous variables were compared between groups using the Student $t$ test or MannWhitney $U$ test. Multivariate logistic regression analysis was used to find independent predictors of CAE. Receiver operating characteristic (ROC) curve was used to evaluate independent risk factors for $\mathrm{CAE}$ and their predictive values. $P$ values $<0.05$ were considered significant.

\section{Results \\ Clinical and demographic characteristics}

Clinical and demographic data of our study population are shown in Table 1. Isolated systolic HTN was found in most of our hypertensive patients (19 with normal coronaries and 22 with CAE). Coronary ectasia had single vessel distribution in 19 patients versus multivessel distribution in 31 patients. According to Markis et al.'s classification [2], 19 patients had type I, 12 patients had type II, 10 patients had type III, and 9 patients had type IV. Left anterior descending coronary (LAD) was affected in 39 cases, left circumflex coronary (LCX) in 21 cases, right coronary artery (RCA) in 33 cases, and left main (LM) coronary artery in only one case. Figure 2 shows ectasia of RCA, LAD, and LCX in one of our study population. fQRS affected inferior leads in 15 cases, anterolateral leads in 15 cases, anterior leads in 11 cases, all leads in 8 cases, lateral leads in 2 cases, anteroseptal leads in one case, and inferior and high lateral leads in one case. There was no significant difference between the 4 types of CAE as regards the incidence of fQRS.

\section{Comparison between the 2 study groups}

Univariate logistic regression analysis showed a significant correlation between male sex, smoking, diabetes mellitus (DM), elevated systolic blood pressure (SBP), fQRS, echocardiographic evidence of left ventricular

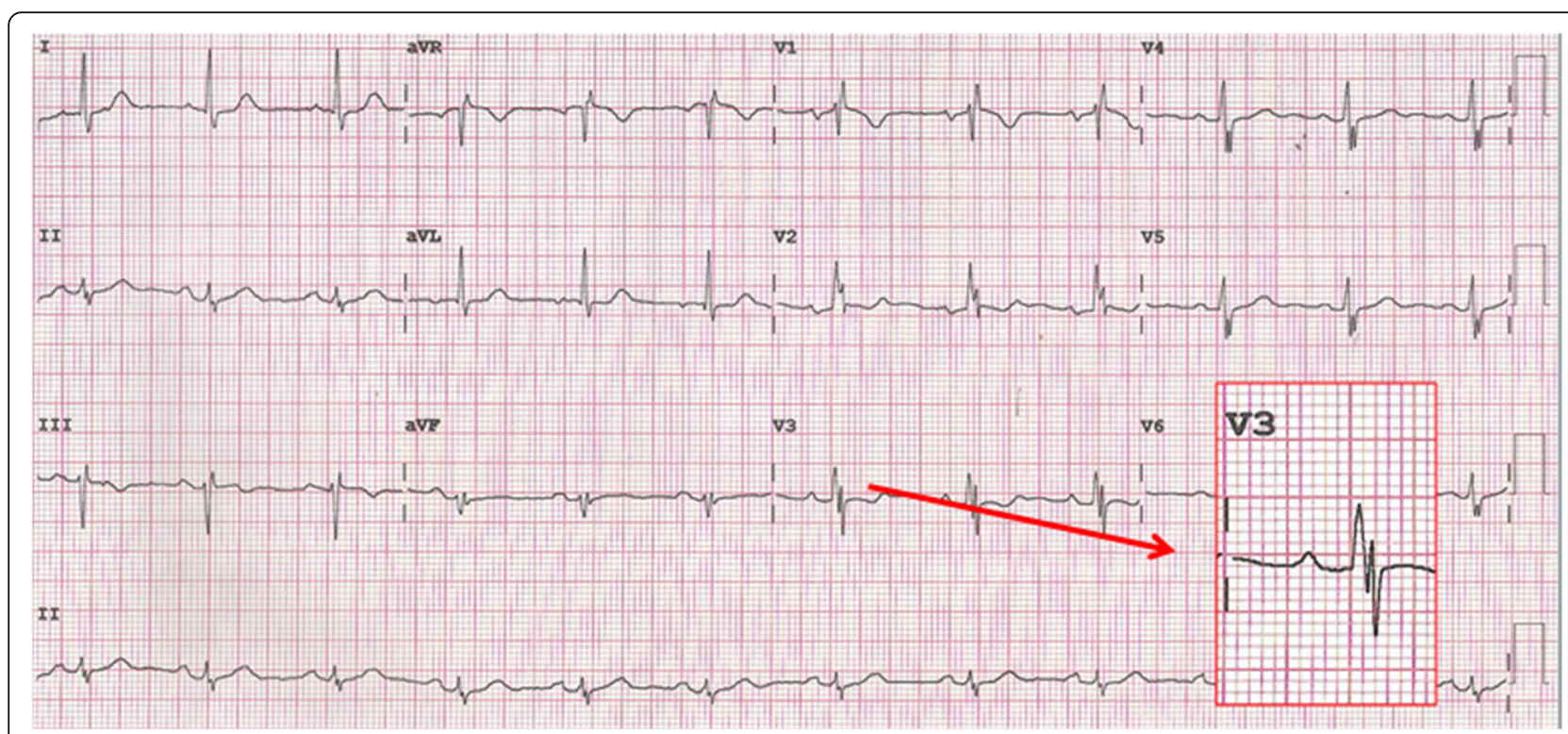

Fig. 1 Twelve-lead surface ECG recording for one of our study population showing different patterns of QRS fragmentation in inferior, anterior, and lateral leads ( $R^{\prime}$ in $V_{1}$, notched $R$ wave in $V_{2}$, notched $S$ wave in $\|$ and $V_{4-6}$ ). This patient was discovered to have $C A E$ in $L A D$, $L C X$, and $R C A$ by invasive CA. A magnified view of lead $V_{3}$ is shown with 2 positive and 2 negative waves with a normal QRS complex duration 
Table 1 Demographic, clinical, ECG, and echocardiographic data of our study population

\begin{tabular}{ll}
\hline Variables & Total \\
\hline Age (years) & $55.10 \pm 9.19$ \\
Male sex & $69(69.0 \%)$ \\
Smoking & $43(43.0 \%)$ \\
Diabetes mellitus & $46(46.0 \%)$ \\
Hypertension & $48(48.0 \%)$ \\
Positive family history of premature IHD & $16(16.0 \%)$ \\
Dyslipidemia & $23(23.0 \%)$ \\
Systolic blood pressure (mmHg) & $125.15 \pm 15.64$ \\
Diastolic blood pressure (mmHg) & $79.20 \pm 10.88$ \\
fQRS & $53(53 \%)$ \\
Pulmonary artery pressure (mmHg) & $36.76 \pm 14.33$ \\
Mitral regurgitation (any grade) & $51(51 \%)$ \\
Diastolic dysfunction (any grade) & $44(44.0 \%)$ \\
\hline
\end{tabular}

diastolic dysfunction (LVDD), and the incidence of CAE ( $P$ values of $0.006,0.003,0.017,0.03,0.0001$, and 0.04 , respectively). Comparison between both groups regarding different variables is shown in Table 2.

Multivariate logistic regression analysis showed that QRS fragmentation in surface ECG is the most important independent predictor of CAE $(P<0.00001$; OR 407.741, 95\% CI 35.417-4694.164). The ROC curve was used to assess the accuracy of using QRS fragmentation in the prediction of CAE, and it showed an overall accuracy of $91 \%$, sensitivity of $94 \%$, specificity of $88 \%$, positive predictive value of $88.7 \%$, and negative predictive value of $93.6 \%$.

\section{Correlation of fQRS distribution on surface ECG and anatomical CAE location}

We found a highly significant correlation between increase in the number of ECG territories affected by fQRS and multivessel affection by CAE $(P=0.00001)$. We also found a highly significant correlation between
LAD ectasia and $\mathrm{fQRS}$ affecting anterior leads [including fragmentation in anterolateral and anteroseptal leads] ( $P$ $=0.00001)$. Our results also showed a significant correlation between LCX ectasia and fQRS affecting lateral leads $(P=0.003)$ followed by inferior leads $(P=0.04)$. Also, a highly significant correlation between RCA ectasia and fQRS affecting inferior leads was found $(P=$ 0.00001).

\section{Discussion}

Our study was an observational prospective case control study that was conducted upon 2 groups (isolated CAE vs. normal coronaries group) each one consisting of 50 patients based on data obtained from invasive CA. We aimed to find out some clinical characteristics that can non-invasively predict the presence of isolated CAE. Univariate analysis showed that there is a significant correlation between male sex, smoking, DM, elevated SBP, fQRS, echocardiographic evidence of LV diastolic dysfunction, and the incidence of CAE. Multivariate analysis showed that fQRS in surface ECG is the most important independent predictor of CAE.

Due to sparsity of data, there is no agreement about definite risk factors for CAE. However, some studies postulated that the classic risk factors for atherosclerotic CAD may have a considerable role in the development of CAE [24, 29].

Many studies showed that male sex is an independent risk factor for CAE [25, 30, 31]. This gender difference suggests a possible protective role of estrogen against the development of CAE.

A significant correlation between smoking and incidence of CAE was found. Similar data were obtained by Boles et al. in their study [23]. On the other hand, Qin et al. [31] in their study failed to prove such a correlation. Despite the association between smoking and CV disease is well proven with solid evidence, yet the exact pathological details of this link are not yet fully understood [32].
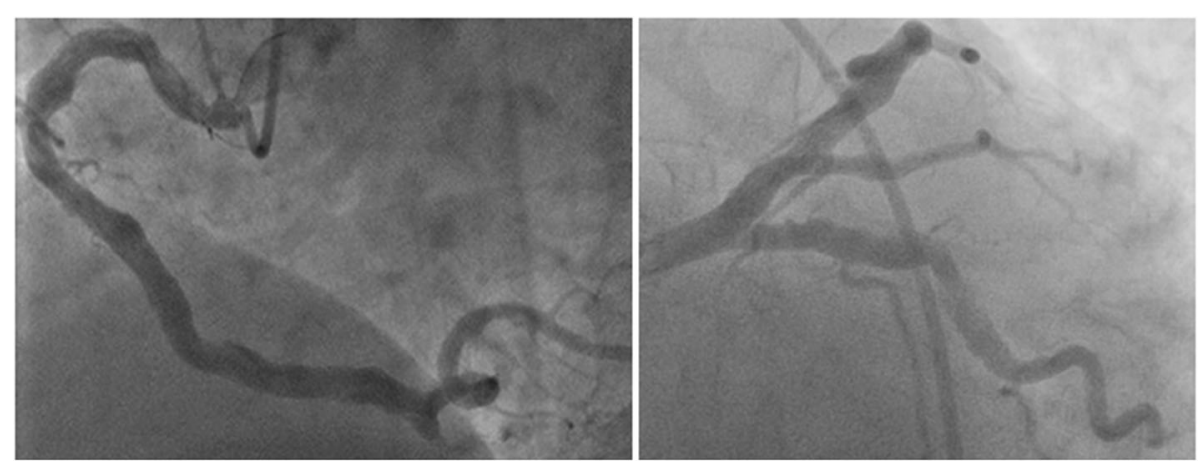

Fig. 2 Coronary angiography of one of our study population showing diffuse ectasia of RCA (left), and LAD and LCX (right) 
Table 2 Comparison between the 2 study groups as regards different study variables

\begin{tabular}{|c|c|c|c|c|}
\hline & & Normal group $(N=50)$ & Ectasia group $(N=50)$ & $P$ value \\
\hline \multicolumn{2}{|l|}{ Age } & $54.02 \pm 9.54(32-70)$ & $56.31 \pm 8.85(36-72)$ & 0.220 \\
\hline \multicolumn{2}{|l|}{ Male sex } & $28(56.0 \%)$ & $41(82.0 \%)$ & 0.005 \\
\hline \multicolumn{2}{|l|}{ Smoking } & $14(28.0 \%)$ & $29(58.0 \%)$ & 0.002 \\
\hline \multicolumn{2}{|l|}{ DM } & $17(34.0 \%)$ & $29(58.0 \%)$ & 0.016 \\
\hline \multicolumn{2}{|l|}{ Dyslipidemia } & $10(20.0 \%)$ & $13(26.0 \%)$ & 0.476 \\
\hline \multicolumn{2}{|c|}{ Family history of premature IHD } & $6(12.0 \%)$ & $10(20.0 \%)$ & 0.275 \\
\hline \multicolumn{2}{|l|}{ Hypertension } & $22(44.0 \%)$ & $26(52.0 \%)$ & 0.423 \\
\hline \multicolumn{2}{|l|}{ SBP } & $121.70 \pm 15.31(100-160)$ & $128.60 \pm 15.35(100-160)$ & 0.027 \\
\hline \multicolumn{2}{|l|}{ DBP } & $78.80 \pm 12.06(60-110)$ & $79.60 \pm 9.68(60-100)$ & 0.715 \\
\hline \multicolumn{2}{|l|}{ QRS fragmentation } & $6(12.0 \%)$ & 47 (94.0\%) & 0.000 \\
\hline \multicolumn{2}{|c|}{ Pulmonary artery pressure (mmHg) } & $36.70 \pm 14.90$ & $36.82 \pm 13.90$ & 0.967 \\
\hline \multirow[t]{4}{*}{ Mitral regurgitation } & Grade 1 & $19(38 \%)$ & $18(36 \%)$ & \multirow[t]{4}{*}{0.663} \\
\hline & Grade 2 & $6(12 \%)$ & $5(10 \%)$ & \\
\hline & Grade 3 & $2(4 \%)$ & $1(2 \%)$ & \\
\hline & Grade 4 & $0(0 \%)$ & $0(0 \%)$ & \\
\hline \multirow[t]{4}{*}{ Diastolic dysfunction } & Grade 1 & $17(34.0 \%)$ & $24(48 \%)$ & \multirow[t]{4}{*}{0.044} \\
\hline & Grade 2 & $0(0 \%)$ & $3(6 \%)$ & \\
\hline & Grade 3 & $0(0 \%)$ & $0(0 \%)$ & \\
\hline & Grade 4 & $0(0 \%)$ & $0(0 \%)$ & \\
\hline
\end{tabular}

The correlation between DM and CV diseases is unquestionable. It is known from literature that even with proper control of glycated hemoglobin and adjustment of all other $\mathrm{CV}$ risk factors, two thirds of patients with type $2 \mathrm{DM}$ are predicted to die suffering from a CV complication [33]. Qin et al. found no significant difference between their study groups regarding incidence of DM [31]. Surprisingly, Bermudez et al. found that absence of DM is an independent predictor for CAE [29]. Diabetic patients on the other side of the spectrum are taking hypoglycemic drugs, statins, and angiotensin blockers which might have a protective effect.

HTN was found to be an independent predictor of CAE in many studies [26, 30, 34, 35]. Kobeissi et al. found in their meta-analysis that hypertensive patients have $66 \%$ higher risk for developing abdominal aortic aneurysm (AAA) than normotensive individuals [35], given a nearly similar pathology in both vascular beds [36]; this finding can be extrapolated to coronary arteries. CAE patients in our study had significantly higher SBP than patients with angiographically normal coronaries (a correlation that proved non-significant in multivariate analysis), but we did not find such a significant difference between both groups regarding DBP. Increased SBP with low or normal DBP is linked to arterial stiffness [37] which is postulated as a protection against arterial aneurysmal dilatation [38], and this can explain the non-significant effect of HTN in our study given that most of our hypertensive patients in both groups had isolated systolic HTN. Also, the correlation between echocardiographic evidence of LVDD and CAE may be indirect via other factors that cause DD as HTN and myocardial ischemia.

Multivariate logistic regression analysis of our study data showed that QRS fragmentation in 12-lead surface ECG is the most important independent predictor of CAE. To our knowledge, the study done by Sen et al. was the only study that discussed the correlation between fQRS and isolated CAE. They found that fQRS is significantly more found in patients with isolated CAE than in patients with normal coronaries [39]. fQRS is more frequently seen in patients with slow coronary flow which is an indicator of microvascular dysfunction [40]. This association between fQRS and coronary slow flow was discussed in some studies as that was done by Mittal [41]. Microinfarctions caused by CAE combined with microvascular dysfunction can be a possible cause for abnormalities in myocardial depolarization resulting in this ECG abnormality. The extremely high incidence of fQRS in our ectasia group might be related to delayed presentation due to decreased medical awareness leading to more subclinical ischemia and microinfarctions. This assumption needs further confirmation in future studies with larger numbers of patients.

To our knowledge, our study is the first one that elucidates the significant correlation between fQRS distribution 
in surface ECG and anatomical distribution of CAE. Our results in this aspect can make us move a further step beyond just using $\mathrm{fQRS}$ as a predictor of CAE towards predicting which artery is affected. These correlations after being confirmed in larger studies can definitely be of utmost importance in more accurate risk stratification of this category of patients.

Our study limitations were the small sample size, and future studies with larger sample sizes will be needed to confirm our results with homogenous distribution of classic cardiovascular risk factors between both groups and allow comparison of fQRS patterns in different types of CAE. Also, the study was done in a single center. We did not use any non-invasive imaging modalities to confirm the association between CAE and scar in the same territory. All our patients were only Caucasians. A larger number of patients are needed to evaluate the separate effect of fQRS in each territory of surface ECG and compare their relative risk, similarly to assess the effect of single vessel ectasia versus multivessel ectasia and the separate risk for affection of each coronary territory. Patients presenting with acute coronary syndromes can be included in future studies. Also, patients with combined ectasia and stenosis need to be studied.

\section{Conclusion}

In conclusion, our study showed that $\mathrm{fQRS}$ is an independent predictor for the presence of isolated CAE and can be used to predict its anatomical distribution. Our results if proved in other studies with larger number of patients can give data for interventional cardiologists about the possibility of facing that challenging abnormality in their patients before going to the cath lab via a simple non-invasive predictor and can also make them anticipate anatomical distribution of CAE using the territorial affection in surface ECG. Finding such a method to anticipate this situation is of utmost importance especially in cases of emergencies if other studies including patients with unstable CAD showed findings similar to ours as it gives an alarm regarding more possible complications and the need for more aggressive anticoagulation approach that may even be started before the procedure after doing the surface ECG. Such finding during routine checkup can also be a drive to start employing intensive risk modification strategies in those patients even before suffering from acute coronary syndromes.

\footnotetext{
Abbreviations

ABP: Arterial blood pressure; CA: Coronary angiography; CAD: Coronary artery disease; CAE: Coronary artery ectasia; DBP: Diastolic blood pressure; DM: Diabetes mellitus; fQRS: Fragmented QRS in 12-lead surface ECG; HTN: Hypertension; LAD: Left anterior descending coronary; LCX: Left circumflex coronary; LVDD: Left ventricular diastolic dysfunction; LVH: Left ventricular hypertrophy; MI: Myocardial infarction; RCA: Right coronary artery; SBP: Systolic blood pressure
}

\section{Acknowledgements}

Technicians and nursing teams of the Cardiology Department of Ain Shams University Hospitals and Damietta Cardiac Center.

\section{Authors' contributions}

DK: establishing the study design, interpretation of CA and ECG data, data analysis, and drafting of the manuscript. MH: interpretation of CA and ECG, and data collection. Both authors read and approved the final manuscript.

\section{Funding}

We did not receive any specific fund to cover this research.

\section{Availability of data and materials}

The datasets used and analyzed during the current study are available from the corresponding author on reasonable request.

\section{Ethics approval and consent to participate}

The study was approved by the Research Ethics Committee (Faculty of Medicine, Ain Shams University, FWA 00006444), and all patients signed an informed written consent for participation in the study in accordance with the Declaration of Helsinki.

\section{Consent for publication}

Not applicable

\section{Competing interests}

The authors declare that they have no competing interests.

\section{Author details}

${ }^{1}$ Cardiology Department, Faculty of Medicine, Ain Shams University, Abbasia Street, Cairo, Egypt. ${ }^{2}$ Damietta Cardiology Center, Damietta, Egypt.

Received: 17 January 2020 Accepted: 25 March 2020

Published online: 15 April 2020

\section{References}

1. Swaye PS, Fisher LD, Litwin P et al (1983) Aneurysmal coronary-artery disease. Circulation 67:134-138. https://doi.org/10.1161/01.CIR.67.1.134

2. Markis JE, Joffe CD, Cohn PF et al (1976) Clinical significance of coronary arterial ectasia. Am J Cardiol 37:217-222. https://doi.org/10.1016/00029149(76)90315-5

3. Kawsara A, Núñez Gil IJ, Alqahtani F et al (2018) Management of coronary artery aneurysms. JACC Cardiovasc Interv 11:1211-1223. https://doi.org/10. 1016/j.jcin.2018.02.041

4. Luo Y, Tang J, Liu X et al (2017) Coronary artery aneurysm differs from coronary artery ectasia: angiographic characteristics and cardiovascular risk factor analysis in patients referred for coronary angiography. Angiology 68: 823-830. https://doi.org/10.1177/0003319716665690

5. Bavry AA, Chiu JH, Jefferson BK et al (2007) Development of coronary aneurysm after drug-eluting stent implantation. Ann Intern Med 146:230232. https://doi.org/10.7326/0003-4819-146-3-200702060-00146

6. Friedman KG, Gauvreau K, Hamaoka-Okamoto A et al (2016) Coronary artery aneurysms in Kawasaki disease: risk factors for progressive disease and adverse cardiac events in the US population. J Am Heart Assoc 5:e003289. https://doi.org/10.1161/JAHA.116.003289

7. Abou Sherif S, Ozden Tok O, Taşköylü Ö et al (2017) Coronary artery aneurysms: a review of the epidemiology, pathophysiology, diagnosis, and treatment. Front Cardiovasc Med 4:24. https://doi.org/10.3389/fcvm.2017. 00024

8. Anabtawi IN, de Leon JA (1974) Arteriosclerotic aneurysms of the coronary arteries. J Thorac Cardiovasc Surg. 68:226-228 PMID: 4546268

9. Krüger D, Stierle U, Herrmann G et al (1999) Exercise-induced myocardial ischemia in isolated coronary artery ectasias and aneurysms ("dilated coronopathy"). J Am Coll Cardiol 34:1461-1470. https://doi.org/10.1016/ s0735-1097(99)00375-7

10. Doi T, Kataoka Y, Noguchi T et al (2017) Coronary artery ectasia predicts future cardiac events in patients with acute myocardial infarction. Arterioscler Thromb Vasc Biol 37:2350-2355. https://doi.org/10.1161/ ATVBAHA.117.309683 
11. Steger A, Sinnecker D, Berkefeld A et al (2015) Fragmented QRS. Relevance in clinical practice. Herzschrittmacherther Elektrophysiol 26:235-241. https:// doi.org/10.1007/s00399-015-0390-6

12. Das MK, Zipes DP (2009) Fragmented QRS: a predictor of mortality and sudden cardiac death. Heart Rhythm 6(3 Suppl):S8-S14. https://doi.org/10. 1016/j.hrthm.2008.10.019

13. Bekler A, Gazi E, Erbag G et al (2014) Relationship between presence of fragmented QRS on 12-lead electrocardiogram on admission and long-term mortality in patients with non-ST elevated myocardial infarction. Turk Kardiyol Dern Ars 42:726-732. https://doi.org/10.5543/tkda.2014.79438

14. Tanriverdi Z, Dursun H, Simsek MA et al (2015) The predictive value of fragmented QRS and QRS distortion for high-risk patients with STEMI and for the reperfusion success. Ann Noninvasive Electrocardiol 20:578-585. https://doi.org/10.1111/anec.12265

15. Sha J, Zhang S, Tang M et al (2011) Fragmented QRS is associated with allcause mortality and ventricular arrhythmias in patient with idiopathic dilated cardiomyopathy. Ann Noninvasive Electrocardiol 16:270-275. https:// doi.org/10.1111/j.1542-474X.2011.00442.x

16. Açikgöz E, Yaman B, Açikgöz SK et al (2015) Fragmented QRS can predict severity of aortic stenosis. Ann Noninvasive Electrocardiol 20:37-42 https:// doi.org/10.1111/anec.12175

17. Nomura A, Konno T, Fujita T et al (2015) Fragmented QRS predicts heart failure progression in patients with hypertrophic cardiomyopathy. Circ J 79: 136-143. https://doi.org/10.1253/circj.CJ-14-0822

18. Temiz A, Gazi E, Altun B et al (2015) Fragmented QRS is associated with frequency of premature ventricular contractions in patients without overt cardiac disease. Anatol J Cardiol 15:456-462. https://doi.org/10.5152/akd.2014.5467

19. Temiz A, Gazi E, Güngör $O$ et al (2014) Fragmented QRS and prediction of paroxysmal atrial fibrillation episodes. Pak J Med Sci 30:862-867 PMID: 25097533

20. Das MK, Maskoun W, Shen C et al (2010) Fragmented QRS on twelve-lead electrocardiogram predicts arrhythmic events in patients with ischemic and nonischemic cardiomyopathy. Heart Rhythm 7:74-80. https://doi.org/10. 1016/j.hrthm.2009.09.065

21. Morita H, Kusano KF, Miura D et al (2008) Fragmented QRS as a marker of conduction abnormality and a predictor of prognosis of Brugada syndrome. Circulation 118:1697-1704. https://doi.org/10.1161/CIRCULATIONAHA.108.770917

22. Haraoka K, Morita H, Saito Y et al (2010) Fragmented ORS is associated with torsades de pointes in patients with acquired long QT syndrome. Heart Rhythm 7:1808-1814. https://doi.org/10.1016/j.hrthm.2010.09.008

23. Boles $U$, Zhao Y, Rakhit R et al (2014) Patterns of coronary artery ectasia and shortterm outcome in acute myocardial infarction. Scand Cardiovasc J. 48: 161-166. https://doi.org/10.3109/14017431.2014.902495

24. Fang CT, Fang YP, Huang YB et al (2017) Epidemiology and risk factors of coronary artery aneurysm in Taiwan: a population based case control study. BMJ Open 7:8. https://doi.org/10.1136/bmjopen-2016-014424

25. Aksu T, Uygur B, Kosar MD et al (2011) Coronary artery ectasia: its frequency and relationship with atherosclerotic risk factors in patients undergoing cardiac catheterization. Anadolu Kardiyol Derg 11:280-284. https://doi.org/ 10.5152/akd.2011.076

26. Saglam M, Karakaya O, Barutcu I et al (2007) Identifying cardiovascular risk factors in a patient population with coronary artery ectasia. Angiology 58: 698-703. https://doi.org/10.1177/0003319707309119

27. Patel MR, Bailey SR, Bonow RO et al (2012) ACCF/SCAI/AATS/ AHA/ASE/ ASNC/HFSA/ HRS/SCCM/SCCT/ SCMR/STS 2012 appropriate use criteria for diagnostic catheterization: a report of the American College of Cardiology Foundation Appropriate Use Criteria Task Force, Society for Cardiovascular Angiography and Interventions, American Association for Thoracic Surgery, American Heart Association, American Society of Echocardiography, American Society of Nuclear Cardiology, Heart Failure Society of America, Heart Rhythm Society, Society of Critical Care Medicine, Society of Cardiovascular Computed Tomography, Society for Cardiovascular Magnetic Resonance, and Society of Thoracic Surgeons. J Am Coll Cardiol 59:19952027. https://doi.org/10.1016/j.jacc.2012.03.003

28. Tigen K, Karaahmet T, Gurel E et al (2009) The utility of fragmented QRS complexes to predict significant intraventricular dyssynchrony in nonischemic dilated cardiomyopathy patients with a narrow QRS interval. Can J Cardiol 25:517-522. https://doi.org/10.1016/s0828-282x(09)70137-0

29. Bermudez EP, Palop RL, Martinez-Luengas IL et al (2003) Coronary ectasia: prevalence, and clinical and angiographic characteristics. Rev Esp Cardiol 56: 473-479 PMID: 12737785
30. Yılmaz H, Sayar N, Yılmaz M et al (2008) Coronary artery ectasia: clinical and angiographical evaluation. Arch Turk Soc Cardiol 36(8):530-535 PMID: 19223718

31. Qin Y, Tang C, Ma C et al (2019) Risk factors for coronary artery ectasia and the relationship between hyperlipidemia and coronary artery ectasia. Coronary Artery Disease 30:211-215. https://doi.org/10.1097/MCA 0000000000000709

32. Kiriyama $\mathrm{H}$, Kaneko $\mathrm{H}$, Itoh $\mathrm{H}$ et al (2019) Effect of cigarette smoking on carotid artery atherosclerosis: a community-based cohort study. Heart Vessels https://doi.org/10.1007/s00380-019-01455-5

33. Gregg EW, Hora I, Benoit SR (2019) Resurgence in diabetes-related complications. JAMA. 321(19):1867-1868. https://doi.org/10.1001/jama.2019. 3471

34. Baman TS, Cole JH, Devireddy CM et al (2004) Risk factors and outcomes in patients with coronary artery aneurysms. Am J Cardiol 93:1549-1551. https://doi.org/10.1016/j.amjcard.2004.03.011

35. Kobeissi E, Hibino M, Pan H et al (2019) Blood pressure, hypertension and the risk of abdominal aortic aneurysms: a systematic review and metaanalysis of cohort studies. Eur J Epidemiol 34:547-555 https://doi.org/10. 1007/s10654-019-00510-9

36. Stajduhar KC, Laird JR, Rogan KM et al (1993) Coronary arterial ectasia: increased prevalence in patients with abdominal aortic aneurysm as compared to occlusive atherosclerotic peripheral vascular disease. Am Heart J. 125:86-92. https://doi.org/10.1016/0002-8703(93)90060-m

37. DeRubertis BG, Trocciola SM, Ryer EJ et al (2007) Abdominal aortic aneurysm in women: prevalence, risk factors, and implications for screening J Vasc Surg. 46:630-635 https://doi.org/10.1016/j.jvs.2007.06.024

38. Rapsomaniki E, Timmis A, George J et al (2014) Blood pressure and incidence of twelve cardiovascular diseases: lifetime risks, healthy life-years lost, and age-specific associations in 1.25 million people. Lancet 383(9932): 1899-1911 https://doi.org/10.1016/S0140-6736(14)60685-1

39. Sen F, Yilmaz S, Kuyumcu MS et al (2014) The presence of fragmented grs on 12-lead electrocardiography in patients with coronary artery ectasia. Korean Circ J 44(5):307-311 https://doi.org/10.4070/kcj.2014.44.5.307

40. Yilmaz H, Gungor B, Kemaloglu T et al (2014) The presence of fragmented QRS on 12-lead ECG in patients with coronary slow flow. Kardiol Pol 72:1419. https://doi.org/10.5603/KP.2013.0181

41. Mittal SR (2016) Fragmented QRS: A simple electrocardiographic prognostic marker in cardiovascular disease. J Clin Prev Cardiol 5:94-98. https://doi.org/ 10.4103/2250-3528.191100

\section{Publisher's Note}

Springer Nature remains neutral with regard to jurisdictional claims in published maps and institutional affiliations.

\section{Submit your manuscript to a SpringerOpen ${ }^{\circ}$ journal and benefit from:}

- Convenient online submission

- Rigorous peer review

- Open access: articles freely available online

High visibility within the field

- Retaining the copyright to your article

Submit your next manuscript at $>$ springeropen.com 